$7_{\text {International Conference on Research in }}^{\text {th }}$

BEHAVIORAL \& SOCIAL SCIENCES

荖

23 - 25 October, $2020 \quad$ Amsterdam,Netherlands

\title{
Television Series Viewing Habits and Trends in Croatia: The Case of Turkish TV Series
}

\author{
M. Sami Okumus Ph.D. ${ }^{1}$, Maja Bradic M.A. ${ }^{2}$ \\ Marmara University/Faculty of Communication-Radio, TV and Cinema
}

\begin{abstract}
.
Television series are among the most important television products and are indispensable as prime-time representatives of a broadcast generation that international television channels put a strong emphasis on. Both the quality of the content and the cultural similarities the audience perceives in the story carry relevance in terms of reaching the target audience. This study aims to deal with the development of the TV series sector in the context of Turkish TV series (TTS) in recent years, regarding the export of these series abroad and the sociological, cultural and philological effects of these series in the countries where they are shown. The main reason for this study is to understand the reasons for the increasing in the number of Turkish TV series which were broadcast in Croatia between 2010 and 2020 (forty-five TTS project), and why they are preferred by the audience and also their effects on local people. Turkish TV series, production details and broadcasting info were analyzed and explained using information obtained from the Croatian audience through an online questionnaire. According to the main results obtained from the questionnaire that Turkish TV series are the most watching TV series among American, European, Latin American and domestic TV series in Croatia which is the most preferred as TV series due to the scenario, the choice, and the harmony of the male and female actors, and then the acting and content factors.
\end{abstract}

Keywords: Croatia, Broadcasting Series, Exporting Series, TV Series Production, Turkey. 